\title{
STUDY ON THE METHOD OF GRAIN HARVESTER HOPPER UNLOADING AND FULL HOPPER SIGNALLING USED
}

\author{
Galin Tihanov ${ }^{1}$, Gergana Petkova ${ }^{2} \&$ Mihail Tsatsarov ${ }^{3}$ \\ ${ }^{1}$ Department of Agricultural Engineering, Faculty of Agriculture, Trakia University, Bulgaria \\ Studentski grad, 6000 Stara Zagora, Bulgaria, e-mail: galin.tihanov@abv.bg \\ ${ }^{2}$ Department of Plant production, Faculty of Agriculture, Trakia University, Bulgaria \\ ${ }^{3}$ Department of Mechanical Engineering, Faculty of Technics and Technologies of Yambol, \\ Trakia University, Bulgaria
}

\begin{abstract}
The paper presents a study on the method of grain harvester hopper unloading and the full hopper signalling used. The studies were conducted on 42 farms. Of these, it was found that only $9 \%$ of the farms were unloaded on the move, in the remaining $91 \%$ the harvesters unloaded at standstill. It has been found that on the studied farms harvesters used the following types of full hopper signalling: no automatic signalling (signalling by stopping and opening of the unloading screw) - 8\%; with one level of automatic signalling - 6\%; with two levels of automatic signalling - $73 \%$; do not use signalling, but go out for unloading at the end of the field after filling the hopper-13\%. Harvesters that had to alert the vehicle for full grain hopper were a total of $62,84 \%$ of which having two levels of automatic signalling, $6 \%$ with one level of automatic signalling and $10 \%$ without signalling.
\end{abstract}

Keywords: grain harvester, grain hopper, harvester performance, joint work of harvester and vehicle.

\section{INTRODUCTION}

The process of grain harvesting is entirely mechanized and is characterized by the simultaneous work of people, combine harvesters, vehicles and other machines that provide this process [11]. Grain harvesting must be completed within a relatively short period of time so as not to allow production losses due to the extended harvesting time $[7,9,10]$. These losses, as a rule, are the greatest in unfavorable climatic conditions. Of great importance is the overall logistics of the process that is related, both to the proper organization and to the choice of different ways and means of performing the individual operations [17].

The successful and timely harvesting of the grain crops depends both on the type of technique used and the organization of its use [6]. In order to ensure high efficiency in grain harvesting (minimum labor, energy and resource costs) it is necessary to create process flow, i.e. to perform the various operations in strict sequence and without interruption [4]. In practice, co-ordination between harvesters and vehicles is carried out by the signalling devices on grain harvesters for filled hoppers [17]. The lack of such coordination is a prerequisite for idling that leads to an extension of the harvest period $[1,6,12,13]$. It was found that with good organization, the waiting time of the vehicle is $9.25 \mathrm{~min}$ in one shift and in poor organization $54.9 \mathrm{~min}$ [5]. Also, in case of premature unloading of incomplete hoppers, the load capacity of the transport vehicle is not used effectively.

Unloading harvesters while moving also does not preclude the need to use signaling for filled grain hoppers. Even when unloading while moving, unloading at standstill is needed due to two reasons. The first reason that necessitates to unload at a standstill is that at starting harvest of the field the hopper is filled before exiting the lane, since there is no harvested space for the vehicle to move alongside the grain harvester. The second reason is when the hopper is filled close to the harvested lane for making a round turn (usually at the end of the field). In this case it is impossible for both machines to move continuously alongside [15]. Niehaus's research shows that over $18 \%$ of unloadings have to be carried out at standstill, even though unloading on the move is acceptable. Logistic systems based on information

IRITIE Vol. 6, No. 2, 2018 ISSN 1314-8788 (print), ISSN 1314-8796 (online), doi: 10.15547/artte.2018.02.003 


\section{DTVID $>$ Ipplied Researches in Technics, Technologies ind Bduration Journal of the Faculty of Technics and Technologies, Trakia University https://sites.google.com/a/trakia-uni.bg/artte/}

technologies are increasingly being used to exchange information and synchronize the operations of harvesters and transport vehicles $[8,14,16]$.

Some of the major grain harvester and tractor manufacturers have systems in place to coordinate the operations of several machines in the field and allow the harvester operator to take control over the vehicle as well during unloading. This maximizes unloading performance on the move. A great advantage in these systems is that they synchronize the running speed of the harvester and the vehicle for even unloading with spilling of the grain [14].

There is yet another system that signals the operators of all vehicles involved in the harvesting process about the precise filling of the grain harvester hopper. The continuous flow of information between the harvester and the vehicles is provided by four sensors located in the grain hopper. This is done by the "quantimeter" module, which measures the grain level in the hopper. This information allows vehicle operators to understand which harvester to move to for unloading the hopper, regardless whether they will be unloading at standstill or in motion. The advantage of this system is that it reduces the time the harvester does not reap. In this way, the vehicle has been signaled and it had started before filling the hopper and thus the productivity of the grain harvester is increased [8].

The objective of the present paper is to study and establish the methods of grain harvester hopper unloading and the existing signaling modes for full hoppers.

\section{METODS}

The study of the method of grain harvester hopper unloading and the signaling modes for full hopper used by them was performed in two ways: by questionnaire and on site during harvesting campaigns. For the study by questionnaire a questionnaire was developed $-A_{1}$ (Figure 1), which was sent to specialists in that area. It was grouped along several questions.

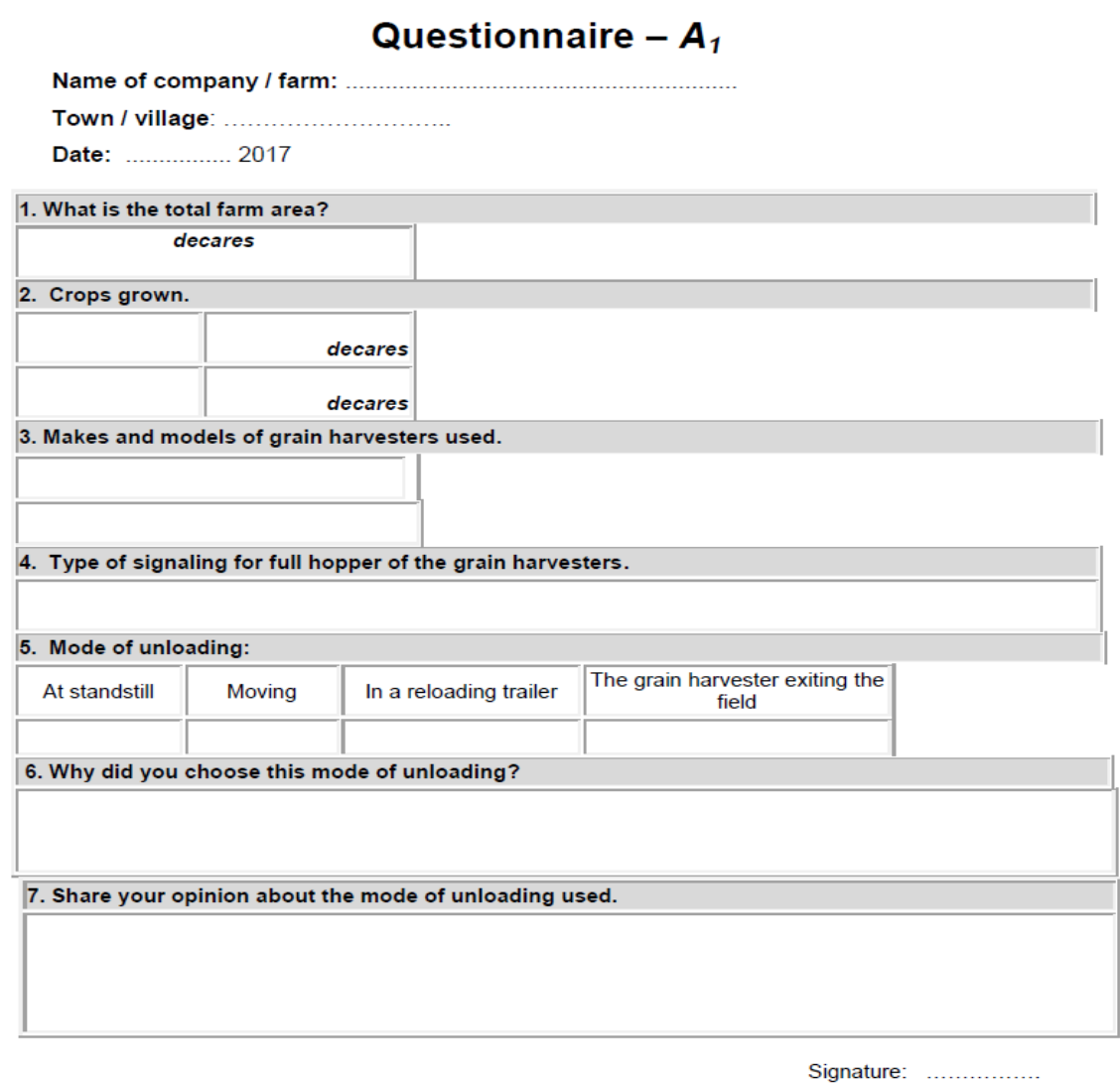

Figure 1. Questionnaire

IRTIIE Vol. 6, No. 2, 2018 ISSN 1314-8788 (print), ISSN 1314-8796 (online), doi: 10.15547/artte.2018.02.003 


\section{IRTITE}

Ipplied Reseircheses in Technics, Technologies ind Educiation

Journal of the Faculty of Technics and Technologies, Trakia University https:///sites.google.com/a/trakia-uni.bg/artte/

The first part of the questions ( 1 to 3 ) aim to study the farm, i.e. what is its area, what crops are grown, and what makes and models of grain harvesters it uses. The second part of the questions (4 and 5) identified the type of signalling and the method of grain hopper unloading, while the third part of the questions ( 6 and 7$)$ asked the operators why they had chosen that method and to share their opinion about it. The survey was conducted in the period 01.03.2017 - 31.04.2017 and covered 23 agricultural farms. The results were grouped on the basis of average values.

On-site surveys during harvesting campaigns were conducted personally on site during harvest from June to November 2017. Figure 2 shows the geographic location of the regions where the surveys were conducted.

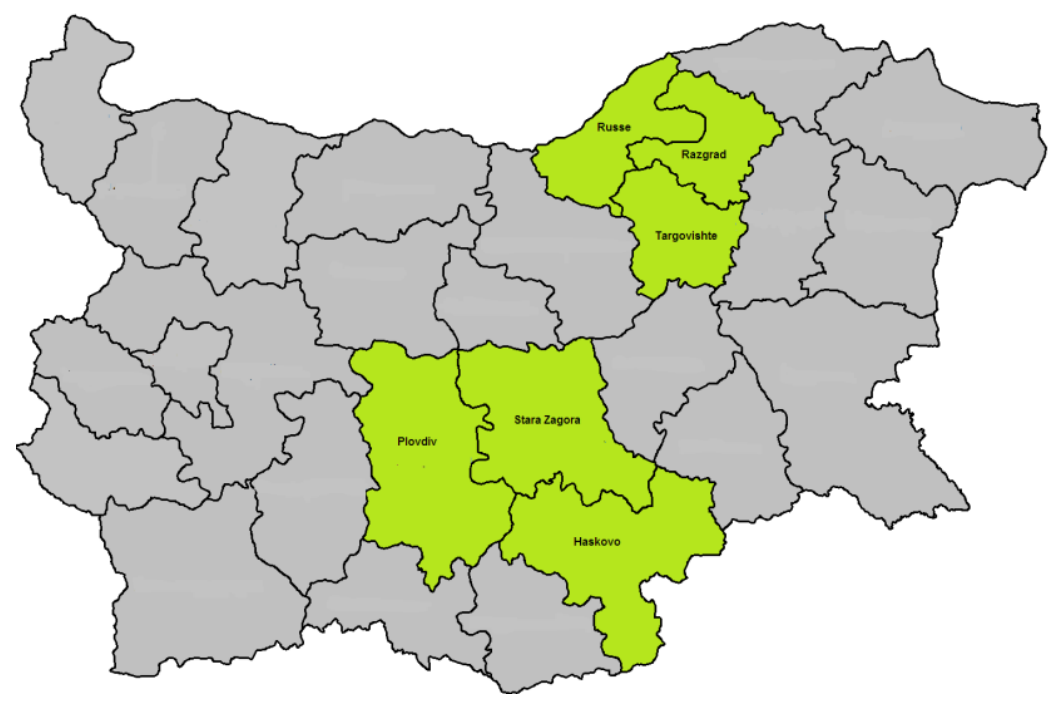

Figure 2. Geographical location of the regions where the surveys have been carried out

\section{RESULTS}

A total of 23 agricultural farms have been studied by questionnaire. Table 1 shows the grain harvesters used on these farms. They are a total of 32 of 23 makes belonging to 11 different brands. In order not to specify the brands (makes) and models of the grain harvesters we have adopted code markings. Capital letters M1, M2, M3, .. M11 denote various grain harvester makes, while small letters $a, b, c \ldots k$ various harvester models, the numbers following them denoting their actual number.

Table 1. Number of grain harvesters by makes and models (acc. to questionnaire)

\begin{tabular}{|c|c|c|c|c|c|c|c|c|c|c|c|c|c|c|c|c|c|c|}
\hline No. & Make & \multicolumn{16}{|c|}{ Model / number } & \multirow{2}{*}{$\begin{array}{c}\begin{array}{c}\text { Total } \\
\text { number }\end{array} \\
1 \\
\end{array}$} \\
\hline 1 & M1 & a1 & 1 & & & & & & & & & & & & & & & \\
\hline 2 & M2 & b1 & 1 & b2 & 2 & & & & & & & & & & & & & 3 \\
\hline 3 & M3 & c1 & 1 & c2 & 5 & c3 & 2 & c4 & 1 & c5 & 1 & c6 & 1 & c7 & 1 & c8 & 2 & 14 \\
\hline 4 & M4 & d1 & 2 & & & & & & & & & & & & & & & 2 \\
\hline 5 & M5 & $\mathrm{e} 1$ & 1 & e2 & 1 & & & & & & & & & & & & & 2 \\
\hline 6 & M6 & $\mathrm{f1}$ & 1 & & & & & & & & & & & & & & & 1 \\
\hline 7 & M7 & g1 & 1 & & & & & & & & & & & & & & & 1 \\
\hline 8 & M8 & h1 & 1 & h2 & 1 & h3 & 2 & h4 & 1 & & & & & & & & & 5 \\
\hline 9 & M9 & i1 & 1 & & & & & & & & & & & & & & & 1 \\
\hline 10 & M10 & j1 & 1 & & & & & & & & & & & & & & & 1 \\
\hline 11 & M11 & k1 & 1 & & & & & & & & & & & & & & & 1 \\
\hline & & & & & & & & & & & & & & & & Tota & & 32 \\
\hline
\end{tabular}

IRITIE Vol. 6, No. 2, 2018 ISSN 1314-8788 (print), ISSN 1314-8796 (online), doi: 10.15547/artte.2018.02.003 
Studies during harvest campaigns were carried out on 19 agricultural farms in different regions in Bulgaria. Table 2 presents the harvesters used on the various farms. These are a total of 39 of 27 models of 10 different brands. The small letters k1, k2, k3, .. k10 denote the different grain harvester makes, while the capital letters A, B , C ... J the different harvester models, the numbers following them also denoting their actual number

Table 2. Number of grain harvesters by makes and models during harvest

\begin{tabular}{|c|c|c|c|c|c|c|c|c|c|c|c|c|}
\hline No. & Make & \multicolumn{10}{|c|}{ Model / number } & Total number \\
\hline 1 & k1 & A1 & 3 & A2 & 1 & A3 & 1 & A4 & 1 & & & 6 \\
\hline 2 & k2 & B1 & 3 & B2 & 2 & B3 & 1 & B4 & 1 & B5 & 1 & 8 \\
\hline 3 & k3 & C1 & 3 & C2 & 1 & C3 & 2 & C4 & 1 & & & 7 \\
\hline 4 & k4 & D1 & 1 & D2 & 4 & & & & & & & 5 \\
\hline 5 & k5 & E1 & 1 & E2 & 1 & E3 & 1 & & & & & 3 \\
\hline 6 & k6 & F1 & 1 & & & & & & & & & 1 \\
\hline 7 & k7 & G1 & 1 & G2 & 1 & & & & & & & 2 \\
\hline 8 & k8 & H1 & 1 & H2 & 1 & H3 & 2 & H4 & 1 & & & 5 \\
\hline 9 & k9 & I1 & 1 & & & & & & & & & 1 \\
\hline 10 & k10 & J1 & 1 & & & & & & & & & 1 \\
\hline
\end{tabular}

Table 3 presents the summarized results of the survey of the prevailing method of grain harvester hopper unloading.

Table 3. Methods of grain harvester hopper unloading

\begin{tabular}{|c|c|c|}
\hline Method of grain harvester hopper unloading & Number & $\%$ \\
\hline Unloading at standstill & 38 & 91 \\
\hline Unloading on the move & 4 & 9 \\
\hline Total: & 42 & 100 \\
\hline
\end{tabular}

From the studied 42 agricultural farms it was established that only $9 \%$ of the farms unload on the move, the remaining $91 \%$ unload at standstill (Table 3 ). The surveys with the questionnaire contained no answer on the question why they had chosen that method of unloading. Informal discussions with the operators revealed the following motives for using that method of unloading:

- $\quad$ easier, no grain spills and that is the tradition on the farm;

- on sloped terrains it is not possible to unload on the move due to dragging the grain to the lower part of the vehicle and difficulty in even filling;

- in case of over-moistened soil, presence of a drainage ditch between the road and the field or in case of undersized area;

- the vehicles used cannot enter the rice „cells“ (mainly in rice harvesting);

- sunflower stubbles intensively destroy the vehicle tyres;

- use of vehicles that are not suitable for moving on stubbles.

One has to not that the last reason becomes more and more topical with the construction of highways in our country and dividing the cultivated areas from the farm storage bases, which necessitates the use of vehicles with big load capacity and high transportation speed.

The main reason for the large-scale grain harvester hopper unloading at standstill is that on most farms they are not aware of the effect of the unloading method on harvester productivity. In that way unloading on the move could significantly reduce the time for crop harvesting.

Table 4 shows the results of the survey on the signaling used for full grain harvester hopper. 
Table 4. Signalling used for full grain harvester hopper

\begin{tabular}{|l|c|c|}
\hline \multicolumn{1}{|c|}{ Signalling used for full hopper } & Number & $\%$ \\
\hline Harvester without automatic signaling for full hopper & 6 & 8 \\
\hline Harvester with one level of automatic signaling for full hopper & 4 & 6 \\
\hline Harvester with two levels of automatic signaling for full hopper & 52 & 73 \\
\hline $\begin{array}{l}\text { With signaling, but the harvester moves to unload to the vehicle located at the end of } \\
\text { the field }\end{array}$ & 9 & 13 \\
\hline
\end{tabular}

Table 4 shows that a total of 71 grain harvesters have been studied. It also shows that $8 \%$ of the grain harvesters have no automatic signalling for full hopper. These are harvesters from an older generation and harvesters with damaged signalling. The operator monitors the filling of the hopper directly through an observation window. A signal is passed to the vehicle driver by stopping the harvester and opening the unloading screw. Usually, the observation windows are located low and filling of the hopper cannot be reported, i.e. filling of the bunkers was subject to subjective judgement. Thus, harvesters make a greater number of stops for unloading, which reduces their productivity.

The table shows that $6 \%$ of the harvesters have one level of automatic signalling for full hopper. In them, the pilot light or buzzer in the cabin informs the operator about filled grain hopper and simultaneously switches on a signal lamp to inform the vehicle driver. These harvesters are also from an older generation when two-level signalling for full hopper was not the standard. This is why all manufacturers (in single-level signaling harvesters) recommend the signalling device to be switched on before the hopper is filled to allow it to hold additional quantity of grain before unloading begins [3]. Naturally, the precise timing of switching on cannot practically be achieved, especially when harvesting on sloped terrains.

The highest percentage (73\%) of the studied harvesters use automatic signalling for two levels of hopper filling. In them, when the first-level signal light is triggered, the vehicle drivers approach and monitor the movement of the harvester, which in the meantime opens the unloading screw. After filling the hopper (second level), the harvester stops and the vehicle comes under the unloading screw. In all harvesters, the positions of the first- and second-level sensors could be adjusted. Their operating manuals recommended the firstlevel sensor to be triggered at $75-80 \%$ filling of the hopper. The second-level sensor (full hopper) is adjusted in such a way that the hopper does not overflow. On sloped terrains it is located at a lower position.

Table 4 shows that $13 \%$ of grain harvesters have two-level signalling, but they move for unloading to the vehicle located at the end of the field. The reasons for this are that it is virtually impossible for the vehicle to enter the rice "cells" (when harvesting rice). The other reason is in fields in which vehicles cannot enter because of over-moistened soil or the presence of a canal, deep shoulder, etc. In fact, $87 \%$ of the studied grain harvesters have automatic signalling for two levels of hopper filling, but $13 \%$ of them do not use it to signal the vehicle for objective reasons. The signalling (for full hopper) is used only by the grain harvester operators to find out when to stop harvesting.

Except for the harvesters that do not signal the vehicle (Table 4), it is evident that the harvesters that have to signal the vehicle after filling the hopper were a total of 62 , with $84 \%$ of them having two levels of automatic signalling, $6 \%$ with one level of automatic signaling and $10 \%$ without signalling (Figure 3 ). 

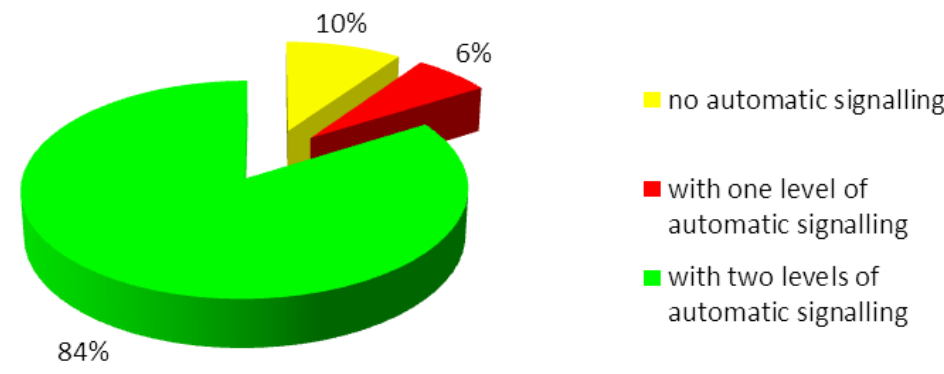

Figure 3. Percentage correlation

of grain harvesters using various types of signaling for hopper filling

\section{CONCLUSIONS}

It has been found that in $91 \%$ of the studied farms grain harvester hopper unloading is done at standstill and only in $9 \%$ the unloading is done on the move.

It has been found that on the surveyed farms harvesters used the following types of full hopper signalling:

- $\quad$ without automatic signaling (signalling with stop and opening of the unloading screw) $8 \%$;

- $\quad$ with one level of automatic signalling - 6\%;

- $\quad$ with two levels of automatic signalling - 73\%;

- do not use signalling but go out to unload at the end of the field - $13 \%$.

A total of $87 \%$ of the surveyed grain harvesters had automatic signaling for two levels of hopper filling, but $13 \%$ of them did not use it to signal the vehicle. Signalling (for full hopper) is only used by the harvester operators to stop harvesting.

It has been found that the harvesters that had to signal the vehicle when the hopper is full were a total of 62 , with $84 \%$ of them having two levels of automatic signalling, $6 \%$ with one level of automatic signalling and $10 \%$ with no signalling for full hopper.

\section{REFERENCES}

[1] Georgieva K. \& Ivanova N. (2014). Determining losses due to idling time of agricultural machines. International scientific conference "management and quality" 2014" for young scientists. A collection of scientific works 17-19, 2014, 143-156, ISSN 1314-4669.

[2] Delchev N. \& Trendafilov K. (2002). Effect of grain harvester hopper volume on their productivity when unloading at standstill, Agricultural machinery No. 3, 2002, 19-22.

[3] Isaacson H. I. (1974). Grain harvesters „Niva“ and „Kolos“, Moscow, 1974.

[4] Kostov Z. \& Dimitrov D. (1975). Operation of the machine tractor fleet, Zemizdat, Sofia, 1975.

[5] Lhagvasuren S. \& Byambadorge Ch. (2013). Comparative study of grain harvesters, materials of International scientific practical conference for yound scientists «Scientific research and development for implementation in the Agroindustrial complexes», 17-18 April 2013, Part II, 233-236.

[6] Tihanov G. (2017). Study of grain harvester hopper unloading time at standstill in relation to optimizing their productivity, Dissertation paper for awarding Doctor's educational and scientific degree, Ruse University „Angel Kanchev“, Ruse, 2017, 140.

[7] Trendafilov K. \& Dragoev D. (2017). Study on the place of grain hopper unloading on the grain harvester productivity, International scientific conference „Technics, technology, education" - ICTTE 2017 of the Faculty of Technics and technology - town of Yambol at Trakia University, Stara Zagora, 19-20.10.2017, Collection of scientific reports, 26-31.

IRTIIE Vol. 6, No. 2, 2018 ISSN 1314-8788 (print), ISSN 1314-8796 (online), doi: 10.15547/artte.2018.02.003 


\section{ARTITE

[8] “Claas Group”. (2015). Less stress but more efficiency in field logistics, 2015, Available: http://www.claas-group.com/press-public-relations/press-releases/less-stress-butmoreefficiency-in-field-logistics/657124.

[9] Delchev N. \& Trendafilov K. (2013). Method for rapid determination of the percentage rate of grain losses by the combine harvester according to its parameters, Agricultural science and technology, Volume 5, Number 1, March 2013, 62-64.

[10] Delchev N. \& Trendafilov K. (2015) Structural Analysis of the Operations and Time for Tank Unloading of Grain Harvesters, International Journal of Science and Research (IJSR), Volume 4, Issue 3, March 2015, 1890-1894.

[11] Delchev N., Trendafilov K., Tihanov G. \& Stoyanov Y. (2016). Grain combines productivity according to various unloading methods-in the field and at the edge of the field, Agricultural science and technology, Volume 8, Number 3, September 2016, ISSN 1313-8820, 221-226.

[12] Georgieva K. \& Ivanova N. (2015). Determining losses due to downtime of machines in agriculture, EMIT- Economigs Manadement Information Technology, Volume 4, Number 1, 2015, 10-17.

[13] Georgieva K., Dragoev D. \& Ivanova N. (2017). Optimization of the number of harvesting and transport complexes in wheat farming, Mechanization in agriculture \& conserving of the resourcs, Yaer LXIII, 2017, 236-238.

[14] "Machine Sync". (2013). Accelerating the fall harvest with John Deere Machine Sync, September 2013, Available: http://blog.machinefinder.com/16353/accelerating-fallharvest-john-deere-machine-sync.

[15] Niehaus Ch. (2014). Evaluation of corn harvesting operations with the use of geo referenced data, University of Illinois at Urbana-Champaign, 2014.

[16] "Telematics: Wireless Communication and Data Transfer". (2012). Precision Agriculture Series, Timely Information, Agriculture, Natural Resources \& Forestry, Alabama Cooperative Extension System, September 2012, [Online], Available: www.AlabamaPrecisionAgOnline.com.

[17] Tihanov G., Kolev B., Trendafilov K., Delchev N. \& Stoyanov Y. (2017). Justification of the method for determining the moment for switching on the level one signaling of filled grain harvester hoppers, Agricultural science and technology, Volume 9, Number 3, September 2017, 218-222. 